\title{
DSM erhöht die Kapazität für Solarbeschichtungen
}

Doyal DSM hat seine installierte IFertigungskapazität für die Antireflexionsbeschichtung KhepriCoat ausgeweitet. Die zusätzliche Kapazität soll seit Ende 2012 am Standort Chemelot im niederländischen Geleen verfügbar sein. Der Bedarf an zusätzlichem Beschichtungsmaterial ist die direkte Folge des Wachstums auf dem Markt für Solarenergie. Die Beschichtung zielt vor allem auf Solaranwendungen ab: hier sorgt die circa 100 bis $150 \mathrm{~nm}$ dünne Schicht auf dem Glas für eine er- hebliche Verringerung der Reflexion des Sonnenlichts. Dadurch kann mehr Licht durch das Glas ins Inne- re des Solarmoduls dringen, so dass die Energieausbeute um bis zu 4 Prozent steigt.

\section{Impreglon übernimmt zwei Oberflächentechnik-Firmen}

$M$ it Wirkung zum 1. Januar 2013 hat Impreglon zwei Oberflächentechnik-Unternehmen, GossmannPAC in Bad Camberg und Alzi Metallveredelung in Wünschendorf/Gera, übernommen. Mit ihren Beschichtungsverfahren ergänzen beide Werke die Angebotspalette und erwei- tern das One-Stop-Shop-Konzept der Gruppe. Während sich Gossmann-PAC auf roboter-gestützte Sicherungs-/ Gleit- und Dichtungsbeschichtungen spezialisiert hat, bietet Alzi Metallveredelung Korrosionsschutzbeschichtungen und Komplettmontagen in den neuen Bundesländern an.
Nach sechs Akquisitionen im vergangenen Jahr geht das Management davon aus, dass 2013 die Buy-and-BuildStrategie mit etwas verringertem Tempo fortgesetzt wird. Mit 29 Standorten in 13 Ländern ist Impreglon einer der weltweit führenden Anbieter auf dem Gebiet der Oberflächentechnik.

\section{Softec - 25 Jahre ERP für Oberflächenveredler}

Diestert ie Softec AG, deutscher Marktführer für ERP-Software in der Oberflächenveredelung, feiert ihr 25-jähriges Jubiläum. 1988 startete das Karlsruher Unternehmen als erster Anbieter für Branchensoftware im Bereich Metallbeschichtung. Heute planen und steuern über 150 Dienstleister aus den Bereichen Galvanik, Pulverbeschichtung, Lackierung, Eloxal, Härten und Strahlen ihre Unternehmensprozesse mit der ERP-Lösung Omnitec. „Ein hohes Maß an Innovationsgeist und hochqualifizierte Mitarbeiter sind ein Eckpfeiler unseres Geschäftserfolgs. Der zweite fußt auf langjährigem, tiefem Branchen-Know-how und einem immer offenen Ohr für die Kunden", fasst Michael Hellmuth, Vorstandsvorsitzender der Softec AG, das Erfolgsrezept seines 22 Mitarbeiter umfassenden Softwarehauses zusammen. Anlässlich des Jubi- läums unterstützt das Unternehmen den Verein „Rote Nasen e. V. Clowns im Krankenhaus", indem es Hunderte roter Nasen an seine Kunden verschickt und für jedes eingesandte Kunden-Foto mit roter Nase fünf Euro spendet. Zum Startschuss der Aktion nahm Rote-Nasen-Unterstützer Sören Anders, Deutschlands jüngster Sternekoch, am 31. Januar 2013 eine Basisspende in Höhe von 1500 Euro entgegen.

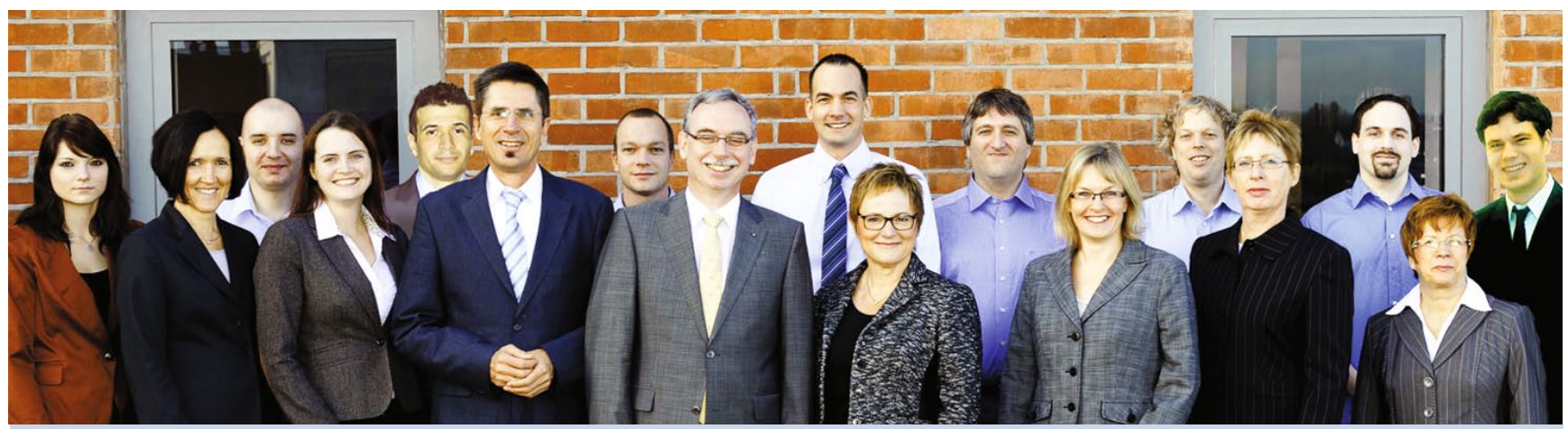

Das Softec-Team um den Vorstandsvorsitzender Michael Hellmuth (vordere Reihe, Mitte) 